\title{
REVIEW
}

\section{Clinical review: Does it matter which hemodynamic monitoring system is used?}

\author{
Davinder Ramsingh, Brenton Alexander and Maxime Cannesson*
}

\begin{abstract}
Hemodynamic monitoring and management has greatly improved during the past decade. Technologies have evolved from very invasive to non-invasive, and the philosophy has shifted from a static approach to a functional approach. However, despite these major changes, the critical care community still has potential to improve its ability to adopt the most modern standards of research methodology in order to more effectively evaluate new monitoring systems and their impact on patient outcome. Today, despite the huge enthusiasm raised by new hemodynamic monitoring systems, there is still a big gap between clinical research studies evaluating these monitors and clinical practice. A few studies, especially in the perioperative period, have shown that hemodynamic monitoring systems coupled with treatment protocols can improve patient outcome. These trials are small and, overall, the corpus of science related to this topic does not yet fit the standard of clinical research methodology encountered in other specialties such as cardiology and oncology. Larger randomized trials or quality improvement processes will probably answer questions related to the real impact of these systems.
\end{abstract}

\section{Introduction}

Does it matter which hemodynamic monitoring system is used? While the question may sound simple, the answer is actually far from being clear. The purpose of a monitoring system is not to treat, but rather to provide clinical information that may impact medical decisionmaking. To quote Michael Pinsky and Didier Payen: 'Finally, no monitoring tool, no matter how accurate, by itself has improved patient outcome' [1]. If we were discussing a medication and asking the question 'Does it

*Correspondence: mcanness@uci.edu

Department of Anesthesiology \& Perioperative Care, University of California, Irvine, 101 S City Drive, Orange, CA 92868, USA matter which drug is used?', the obvious answer would be 'Of course it matters! We should use the drug that has demonstrated the best positive impact on patients' outcome in large randomized controlled trials, the least side effects, and the best price. This would be a straightforward question with a straightforward answer. So why does the same question lead to so much confusion when it refers to hemodynamic monitoring systems?

Hemodynamic monitoring systems are measurement tools and their effects on outcomes are only as good as the protocols they are used to drive. Hemodynamic monitoring in the critical care setting and in the perioperative period has been studied for decades and has generated a still increasing number of publications. It is probably one of the most frequently featured topics in scientific journals and meetings, and one of the most popular focuses for symposiums. During the past 50 years we have observed dramatic changes in technologies available for hemodynamic monitoring, ranging from very invasive to mini-invasive and eventually totally noninvasive technologies [2-4]. At the same time, we have observed a conceptual shift in philosophy from the monitoring of static parameters to functional and dynamic approaches of hemodynamics [5]. Despite all these changes and 'improvements', it is still unclear whether or not it matters which hemodynamic monitoring system we use in clinical practice. We will see that the answer to this question may actually be context dependent [6-8]. The outcome most probably depends on the clinical setting (emergency department, operating room or ICU), on the hemodynamic situation the clinician tries to solve, and partially on the institution, the country and on the healthcare system where the clinician is practicing. Of course, it also depends on the protocol the clinician aims to apply to his or her patient and on the specific goal he or she wants to target (touching on the concept of goal-directed therapy [8-10]).

Eventually, the question remains as to how a hemodynamic monitoring system should be evaluated. Of course, evaluating the impact on patient outcome should be the most important factor [11]. However, can we reasonably expect a hemodynamic monitoring system to improve patient outcome in the critical care setting? For 
instance, the pulse oximeter, which has been evaluated in randomized controlled trials conducted in more than 20,000 patients in the anesthesiology setting, has never been shown to improve patient outcome [12,13]. In the same vein, there is no large randomized controlled trial showing that transesophageal echocardiography can improve patient survival even in the cardiac surgery setting [14]. Do we interpret this to mean that these devices should not be used in the clinical setting?

A few studies, especially in the perioperative period, have suggested that hemodynamic monitoring systems coupled with treatment protocols can improve patient outcome. These trials are small and, overall, the corpus of science related to this topic does not yet fit the standard of clinical research methodology encountered in other specialties such as cardiology and oncology. Larger randomized trials, quality improvement processes, and comparative effectiveness research studies will probably answer questions related to the real impact of these systems.

The term hemodynamic monitoring system is very broad and many concepts could be included under this terminology. The definition could range from microcirculation and mitochondrial function monitoring to arterial pressure and heart rate monitoring. In the present article, we will focus our discussion on systems monitoring cardiac output (CO) and functional hemodynamic parameters. Several review articles have been published recently detailing the different hemodynamic monitoring systems available, and we refer the readers to these manuscripts for an in-depth technological understanding of these systems $[3,4,8,15]$.

The present paper is divided into three parts. In the first part we will describe the evolution of hemodynamic monitoring in the critical care environment during the past 50 years (from the pulmonary artery catheter (PAC) to the most recent functional hemodynamic monitoring). In the second part, we will analyze how these systems have been evaluated in the clinical practice (accuracy for $\mathrm{CO}$ monitors and predictive value for functional hemodynamic parameters) and we will analyze the impact of these systems on patient outcome. Lastly, in the third section, we propose a plan for the use of hemodynamic monitoring systems in critical care settings based on the specific clinical situation, the protocol to be applied, and on the patient. This approach is based on the model of clinical pathways and quality improvement processes implementation.

\section{Hemodynamic monitoring in the critical care setting: from past to present Pulmonary artery catheter}

Intermittent thermodilution obtained through the PAC has been considered the gold standard for $\mathrm{CO}$ monitoring in the clinical setting since the late 1960s [16-18]. This system was widely used until the 1990s [19], when it started to dramatically decrease in all settings [20] secondary to a shift in philosophy, replacement by newer technologies [21], and also probably due to the widespread use of transesophageal echocardiography. Most studies focusing on the PAC and outcome have shown no positive association between PAC use for fluid management and survival in the ICU [22-24] or in the high-risk surgery patient [25]. This conclusion combined with the extreme level of invasiveness, advanced level training for placement, and incorrect parameter interpretation have lead to declining use of this system [26]. However, the PAC still holds utility in the assessment of right ventricular $\mathrm{CO}$, pulmonary arterial pressures [6,8], and mixed venous oxygen saturation monitoring [8,27]. The lack of positive impact of the PAC on patient outcome does not preclude its use in a selected sample of patients by adequately trained physicians. In addition, most new $\mathrm{CO}$ monitoring systems are still evaluated against the intermittent thermodilution technique in the clinical research practice [8].

\section{Esophageal Doppler}

Simultaneous to the decline of PAC use, development of less invasive hemodynamic monitoring systems started in the 1990s. One of the first systems to be described and developed was the esophageal Doppler system allowing for non-invasive monitoring of $\mathrm{CO}$ [28]. This approach was described in the mid-1970s [29,30] and gained popularity in the 1990s after several small studies demonstrated a positive impact on postoperative outcome in patients undergoing high-risk surgery [31-34]. The waveform is highly dependent on correct positioning and requires frequent adjustments of depth, orientation, and gain to optimize the signal [35] and, while esophageal Doppler has demonstrated utility in aiding the assessment of the hemodynamic status of critically ill patients, this technology has been slow to be adopted [36]. This system has the most evidence regarding improvement of outcome in patients undergoing high-risk surgery and therefore should be strongly considered in such a setting [37-41]. The National Health Service in the UK has recently recommended the use of this device during high-risk surgery $[42,43]$.

\section{Transpulmonary thermodilution}

One of the most successful systems to be described has been transpulmonary thermodilution together with the concept of pulse contour analysis. This system was developed in the 1990s by a German company, Pulsion, who commercialized the PiCCO system (Pulsion, Munchen, Germany) [44]. This system, which requires the use of a dedicated arterial line (preferentially femoral) 
and a central venous catheter in the superior vena cava, achieved reasonable acceptance in Europe but is still relatively unknown in the USA [36]. Recently, Edwards Lifesciences released a similar transpulmonary thermodilution system (Volume View; Edwards Lifesciences, Irvine, CA, USA) [45,46]. CO measurements obtained using these systems correlate well with the PAC measurements [47-50]. These systems allow for continuous $\mathrm{CO}$ measurements using the calibrated pulse contour analysis method. While interesting, this method remains invasive [51] and requires frequent recalibration when the vasomotor tone changes [52-55]. Today, these systems have gained popularity in the ICU but are still rarely used in the operating rooms. Additionally, few outcome studies have been published using this system [56] and it is not clear whether their benefits outweigh the risks associated with femoral line placement.

\section{Mini-invasive and non-invasive cardiac output monitoring systems}

More recently, mini-invasive and non-invasive hemodynamic monitoring systems have been developed and deployed [57]. Most mini-invasive systems rely on the analysis of the arterial pressure waveform combined with the patients' demographics [58]. The systems are not user dependent and are very easy to use (plug-and-play). The main drawback of these systems is that they are highly dependent on vasomotor tone and on vascular compliance. Any acute change in these variables impacts the accuracy of these systems $[54,59,60]$. There are limited, but positive, outcome studies using these systems [61,62].

Finally, totally non-invasive systems have been developed. Bioimpedance and, more recently, bioreactance systems are back in the game (bioimpedance was actually developed very early on, before esophageal Doppler, but was never quite successful in the critical care setting) [63-68]. Ultrasound techniques such as the USCOM device have been proposed in the intensive care and emergency department settings (USCOM, Sydney, Australia). More innovative, uncalibrated and noninvasive $\mathrm{CO}$ measurements obtained through the analysis of a non-invasive arterial pressure waveform have also been released recently $[69,70]$. However, we need more evidence regarding the accuracy of these systems in order to use the output variables for clinical decision-making.

Table 1 summarizes the different $\mathrm{CO}$ monitoring systems clinically available today.

\section{Functional hemodynamic monitoring parameters}

Apart from the technological development of $\mathrm{CO}$ monitoring systems, most of the recent medical literature focusing on hemodynamic monitoring in the critical care setting has focused on the so-called functional hemodynamic monitoring parameters [1]. Instead of monitoring a given parameter, functional hemodynamic monitoring assesses the effect of a stressor on a hemodynamic parameter. For the assessment of preload dependence, the stress has been established as a fluid challenge and the parameter monitored is the stroke volume or one of its surrogates (for example, arterial pressure) [71]. The effects of positive pressure ventilation on preload and stroke volume are used to detect fluid responsiveness in mechanically ventilated patients under general anesthesia [5]. If mechanical ventilation induces prominent respiratory variations in stroke volume [5], systolic pressure [72-74] or in arterial pulse pressure (PPV) [75], the patient's heart is more likely to be working on the steep portion of the Frank-Starling relationship and is thus preload dependent. These effects can also be assessed by measuring the variability on the inferior [76,77] or superior [78] vena cava diameter. When these parameters cannot be used because one limitation is present (spontaneous ventilation [79], arrhythmia [80], tidal volume $<7 \mathrm{ml} / \mathrm{kg}$ [81], open chest conditions [82]), the effects of passive leg raising on the stroke volume can be used to detect preload dependence instead [83].

Monnet and colleagues have also described the effects of a tele-expiratory occlusion on arterial pulse pressure to predict the effects of volume expansion on CO [84]. The tele-expiratory occlusion test consists of a 15-second end-expiratory occlusion in patients under mechanical ventilation. Patients presenting a more than $5 \%$ increase in pulse pressure (systolic pressure - diastolic pressure) are more likely to be responders to volume expansion (in these patients, the increase in venous return induced by the decrease in intrathoracic pressure induces an increase in stroke volume and pulse pressure because the patient's heart is working on the steep portion of the FrankStarling curve). These maneuvers (passive leg raising and tele-expiratory occlusion tests) are more appropriate for the ICU setting while stroke volume variation, PPV or respiratory variations in the plethysmographic waveform [85] are more suited for the operating room setting.

These dynamic parameters have consistently been shown to be superior to static parameters for the prediction of fluid responsiveness [75,86]. Moreover, some studies have suggested that minimization of the respiratory variations in the arterial pressure or in the plethysmographic waveforms could improve fluid management and postoperative outcome $[10,87,88]$. Table 2 presents the various functional hemodynamic parameters available for the prediction of fluid responsiveness as well as the monitors available for their display.

\section{Evaluation of hemodynamic monitoring systems and how to choose among them?}

Now that we have discussed the different hemodynamic systems available, the question remains as to whether or 
Table 1. Available cardiac output monitoring systems with their respective advantages and disadvantages

\begin{tabular}{|c|c|c|c|c|c|c|}
\hline Technology & System & Invasiveness & Mechanism & Advantages & Disadvantages & $\begin{array}{c}\text { Outcome } \\
\text { studies }\end{array}$ \\
\hline $\begin{array}{l}\text { Pulmonary artery } \\
\text { catheter }\end{array}$ & Vigilance & +++ & Thermodilution & $\begin{array}{l}\text { Gold standard for continuous/ } \\
\text { intermittent cardiac output } \\
\text { monitoring. Allows measuring } \\
\text { pulmonary pressures and mixed } \\
\text { venous oxygen saturation. }\end{array}$ & $\begin{array}{l}\text { No dynamic parameters } \\
\text { of fluid responsiveness, } \\
\text { Provides cardiac output } \\
\text { information every few } \\
\text { minutes. }\end{array}$ & - \\
\hline \multirow[t]{3}{*}{$\begin{array}{l}\text { Calibrated pulse } \\
\text { contour analysis }\end{array}$} & PiCCO plus & ++ & $\begin{array}{l}\text { Transpulmonary } \\
\text { thermodilution }+ \\
\text { pulse contour analysis }\end{array}$ & $\begin{array}{l}\text { Continuous cardiac output } \\
\text { monitoring. Central venous } \\
\text { oxygen saturation with specific } \\
\text { device. Good accuracy. }\end{array}$ & $\begin{array}{l}\text { Remains significantly } \\
\text { invasive. Requires a } \\
\text { specific femoral artery } \\
\text { catheter. }\end{array}$ & 0 \\
\hline & VolumeView & ++ & $\begin{array}{l}\text { Transpulmonary } \\
\text { thermodilution }+ \\
\text { pulse contour analysis }\end{array}$ & $\begin{array}{l}\text { Continuous cardiac output } \\
\text { monitoring. Central venous } \\
\text { oxygen saturation with specific } \\
\text { device. Good accuracy. }\end{array}$ & $\begin{array}{l}\text { Remains significantly } \\
\text { invasive. Requires a } \\
\text { specific femoral artery } \\
\text { catheter. }\end{array}$ & 0 \\
\hline & LiDCO plus & + & Lithium dilution & $\begin{array}{l}\text { Continuous cardiac output } \\
\text { monitoring. }\end{array}$ & & + \\
\hline \multirow[t]{5}{*}{$\begin{array}{l}\text { Uncalibrated pulse } \\
\text { contour analysis }\end{array}$} & FloTrac & + & Pulse wave analysis & $\begin{array}{l}\text { Continuous cardiac output } \\
\text { monitoring. Mini-invasive, self- } \\
\text { calibration systems. }\end{array}$ & $\begin{array}{l}\text { Accuracy of cardiac } \\
\text { output has been a } \\
\text { concern. Sensitive to } \\
\text { changes in vasomotor } \\
\text { tone. Requires a specific } \\
\text { arterial pressure sensor. }\end{array}$ & + \\
\hline & LiDCO Rapid & + & Pulse wave analysis & $\begin{array}{l}\text { Continuous cardiac output } \\
\text { monitoring. Mini-invasive, } \\
\text { self-calibration systems. Can be } \\
\text { used with any arterial line and } \\
\text { arterial pressure sensor. }\end{array}$ & $\begin{array}{l}\text { Not enough validation } \\
\text { studies. }\end{array}$ & 0 \\
\hline & Pulsioflex & + & Pulse wave analysis & $\begin{array}{l}\text { Continuous cardiac output } \\
\text { monitoring. Mini-invasive, } \\
\text { self-calibration systems. Can be } \\
\text { used with any arterial line and } \\
\text { arterial pressure sensor. }\end{array}$ & No validation study. & 0 \\
\hline & PRAM & + & Pulse wave analysis & $\begin{array}{l}\text { Continuous cardiac output } \\
\text { monitoring. Mini-invasive, self- } \\
\text { calibration systems. }\end{array}$ & $\begin{array}{l}\text { Not enough validation } \\
\text { studies. Requires a } \\
\text { specific arterial kit. }\end{array}$ & 0 \\
\hline & Nexfin & 0 & $\begin{array}{l}\text { Non-invasive pulse } \\
\text { wave analysis }\end{array}$ & $\begin{array}{l}\text { Continuous cardiac output } \\
\text { monitoring. Completely non- } \\
\text { invasive, self-calibration system. }\end{array}$ & $\begin{array}{l}\text { Not enough validation } \\
\text { study. Motion artifact. }\end{array}$ & 0 \\
\hline \multirow[t]{2}{*}{ Ultrasound } & Cardio Q & $0+$ & Doppler ultrasound & $\begin{array}{l}\text { Less invasive then arterial-based } \\
\text { systems, qualifies for billable } \\
\text { monitoring in the USA. }\end{array}$ & $\begin{array}{l}\text { Requires frequent } \\
\text { manipulation for proper } \\
\text { position, significant } \\
\text { potential for user } \\
\text { variability. }\end{array}$ & +++ \\
\hline & USCOM & 0 & $\begin{array}{l}\text { Suprasternal } \\
\text { ultrasound }\end{array}$ & $\begin{array}{l}\text { Non-invasive cardiac output } \\
\text { measurement. }\end{array}$ & $\begin{array}{l}\text { Intermittent. Operator } \\
\text { dependent. }\end{array}$ & 0 \\
\hline Bioreactance & $\mathrm{NiCOM}$ & 0 & Bioreactance & $\begin{array}{l}\text { Non-invasive continuous } \\
\text { cardiac output monitoring. }\end{array}$ & $\begin{array}{l}\text { Few validation studies. } \\
\text { Many limitations. }\end{array}$ & 0 \\
\hline $\begin{array}{l}\text { Endotracheal } \\
\text { bioimpedance }\end{array}$ & ECOM & + & Bioimpedance & $\begin{array}{l}\text { Mini-invasive and continuous } \\
\text { cardiac output monitoring. }\end{array}$ & $\begin{array}{l}\text { Few validation studies. } \\
\text { Requires a specific } \\
\text { arterial kit and a specific } \\
\text { endotracheal tube. }\end{array}$ & 0 \\
\hline $\begin{array}{l}\text { Thoracic } \\
\text { bioimpedance }\end{array}$ & $\mathrm{BioZ}$ & 0 & Bioimpedance & $\begin{array}{l}\text { Non-invasive cardiac output } \\
\text { measurement. }\end{array}$ & $\begin{array}{l}\text { Many negative studies } \\
\text { in the critical care } \\
\text { setting. }\end{array}$ & 0 \\
\hline
\end{tabular}

0, None; 0+, very slight; + slight; ++, intermediate; +++, severe. PiCCO plus, Pulsion Medical Systems, Irving, TX, USA; VolumeView, Edwards, Irvine, CA, USA: LiDCO plus, LiDCO Ltd, London, UK; FloTrac, Edwards, Irvine, CA, USA; LidCO Rapid, LiDCO Ltd, London, UK; Pulsioflex, Pulsion Medical Systems, Irving, TX, USA; PRAM, Multiple Suppliers; Nexfin, BMEye, Amsterdam, Netherlands; Cardio Q, Deltex Medical Limited, Chichester, West Sussex, UK; USCOM, Uscom, Sydney, Australia; NiCOM, Cheetah Medical, Tel Aviv, Israel; ECOM, ConMed, Irvine, CA, USA; BioZ, CardioDynamics, San Diego, CA, USA. 
not it matters which of them is used for the management of critically ill patients. Practically speaking, if we want to reasonably answer this question, we need to define what we expect from these systems, to identify the setting in which the system is going to be used, and to evaluate whether or not these systems accurately achieve what we expect from them.

\section{What do we expect from a hemodynamic monitoring system?}

This question depends on the monitor. At the very least, we expect a $\mathrm{CO}$ monitoring system to measure $\mathrm{CO}$ accurately and we expect a fluid responsiveness monitor to predict fluid responsiveness accurately.

\section{Evaluating the accuracy of a cardiac output monitoring system}

The last two decades have seen an explosion in the numbers of manuscripts published aiming at evaluating the accuracy of a hemodynamic monitoring system to measure $\mathrm{CO}$ accurately. Dozens of manuscripts have tried to define the methodology that should be used to clearly demonstrate whether or not a monitor can measure and track $\mathrm{CO}$ in the clinical setting. After more than a decade of research on this methodology alone, a consensus seems to have been reached [89-92]. The first step is to evaluate the agreement between the new method and the gold standard (most studies still use intermittent thermodilution as the gold standard). For this purpose, Bland-Altman analysis - originally described to assess the agreement between two methods of clinical measurement - should be used [93,94]. This analysis provides the users with a bias and limits of agreement. Unfortunately, little is known with regard to what is considered acceptable or not.

The second step is to calculate the mean percentage error, which is defined as the ratio between the range of the limits of agreement and the mean $\mathrm{CO}$ of the gold standard [95]. The idea is that narrow limits of agreement may mean that the system is very precise, but one must acknowledge that this may also only indicate the study was conducted in a sample of subjects presenting with very low $\mathrm{CO}$ values. According to Critchley and Critchley, a mean percentage error $>30 \%$ should allow the conclusion of the new method as being inaccurate [95]. Once again, one must remember that this approach depends on the intrinsic precision of the gold standard [96]. The third step is then to test the concordance between the new method and the gold standard [97,98]. Basically, this approach aims at evaluating whether or not the two techniques follow the same direction when $\mathrm{CO}$ is modified. For some, a weak accuracy may not be a problem as long as the ability to track changes is accurate. This is theoretically true since most goal-directed therapy
Table 2. Systems allowing for monitoring dynamic parameters of fluid responsiveness

\begin{tabular}{|c|c|}
\hline $\begin{array}{l}\text { Dynamic parameter of } \\
\text { fluid responsiveness }\end{array}$ & $\begin{array}{l}\text { Monitor available for } \\
\text { their display }\end{array}$ \\
\hline Systolic pressure variation & Can be eyeballed accurately \\
\hline \multirow[t]{10}{*}{ Pulse pressure variation } & Cannot be eyeballed \\
\hline & Philips Intellivue Monitors \\
\hline & LiDCO Rapid \\
\hline & LiDCO Plus \\
\hline & PiCCO Plus \\
\hline & PulsioFlex \\
\hline & PRAM \\
\hline & Nexfin \\
\hline & CNAP \\
\hline & General Electric Monitors \\
\hline \multirow[t]{10}{*}{ Stroke volume variation } & LiDCO Rapid \\
\hline & LiDCO Plus \\
\hline & PiCCO Plus \\
\hline & Pulsioflex \\
\hline & PRAM \\
\hline & Vigileo FloTrac \\
\hline & EV1000 VolumeView \\
\hline & ECOM \\
\hline & $\mathrm{BioZ}$ \\
\hline & $\mathrm{NICOM}$ \\
\hline Pleth variability index & Masimo Radical 7 \\
\hline Passive leg raising & $\begin{array}{l}\text { Demonstrated with esophageal } \\
\text { Doppler, PiCCO plus, } \\
\text { Echocardiography, NICOM, and } \\
\text { Vigileo FloTrac }\end{array}$ \\
\hline
\end{tabular}

PiCCO plus, Pulsion Medical Systems, Irving, TX, USA; VolumeView, Edwards, Irvine, CA, USA; LiDCO plus, LiDCO Ltd, London, UK; FloTrac, Edwards, Irvine, CA, USA; LidCO Rapid, LiDCO Ltd, London, UK; Pulsioflex, Pulsion Medical Systems, Irving, TX, USA; PRAM, Multiple Suppliers; Nexfin, BMEye, Amsterdam, Netherlands; Cardio Q, Deltex Medical Limited, Chichester, West Sussex, UK; USCOM, Uscom, Sydney, Australia; NiCOM, Cheetah Medical, Tel Aviv, Israel; ECOM, ConMed, Irvine, CA, USA; BioZ, CardioDynamics, San Diego, CA, USA; CNAP, CNS Systems, Graz, Austria; General Electric Monitors, General Electric Company, Fairfield, Connecticut, USA; EV1000 VolumeView, Edwards, Irvine, CA, USA; Masimo Radical 7, Masimo, Irvine, CA, USA; esophageal Doppler, Deltex Medical Limited, Chichester, West Sussex, UK; Echocardiography, Multiple Suppliers.

protocols for fluid management rely on relative changes in $\mathrm{CO}$, as opposed to absolute values. However, a perfect trending ability together with a weak accuracy would essentially indicate that further calibration would solve the problem. Unfortunately, it is more likely that the bias and the limits of agreement drift over time. According to Critchley and colleagues, concordance $<92 \%$ should be considered inacceptable.

\section{Evaluating the predictive value of a functional hemodynamic parameter}

The use of functional hemodynamic monitoring in the clinical practice is, in a way, simpler to evaluate. The goal of most functional hemodynamic monitoring parameters 
is to predict fluid responsiveness in critically ill patients. For this purpose, the methodology is quite straightforward and has for a long time relied on the use of receiver operating characteristics curve analysis [99]. This analysis results in a single threshold value associated with a high sensitivity and specificity for the prediction of fluid responsiveness. For example, it was shown initially that PPV $>13 \%$ in septic patients was able to predict fluid responsiveness with sensitivity and specificity >90\% [100]. However, this methodology is very old and may not reflect the actual clinical setting where such polarized situations do not often exist.

Significant improvements have recently been made in the methodology used for the evaluation of a biomarker or diagnostic tool [101]. For instance, the gray zone approach has been proposed to avoid the binary constraints resulting from the black-or-white nature of the receiver operating characteristics curve that often does not fit the reality of clinical or screening practice [101]. The gray zone technique proposes two cutoff values that constitute the borders of the gray zone. The first cutoff allows the practitioner to exclude the diagnosis (fluid responsiveness in the present case) with near-certainty (that is, privilege sensitivity and negative predictive value), whereas the second cutoff is chosen to indicate the value above which the selected diagnosis can be included with near-certainty (that is, privilege specificity and positive predictive value) [101]. Intermediate values included in the gray zone correspond to a prediction value not precise enough for a diagnostic decision [102]. This approach has recently been applied to test the ability of PPV to predict fluid responsiveness in the perioperative setting, and it was shown, in more than 400 patients, that the gray zone for PPV is between 8 and $13 \%$ and that about $25 \%$ of the patients are within this gray zone. If this approach was used in the ICU setting, the majority of patients would more likely be within this gray zone. This type of approach should help to better define the clinical application of these functional hemodynamic parameters. In any case, these dynamic parameters have consistently been shown to be the best predictors of fluid responsiveness $[75,86]$.

\section{Evaluating the impact on outcome}

Finally, the ultimate test is to evaluate whether or not the use of a monitor to guide hemodynamic management can improve patient outcome.

The problem is that none of the $\mathrm{CO}$ monitoring systems available today consistently present with $<30 \%$ mean percentage error, $>92 \%$ concordance, and positive outcome studies. Most widely used CO monitoring systems demonstrate a mean percentage error of around 40 to $45 \%$ [103] and most of these devices present with concordance $<92 \%$. Interestingly, despite these very disappointing results, these systems have still been tested in clinical outcome studies and some have demonstrated positive results $[37,104]$. Let us stress this point and be a little bit provocative: it is surprising to observe that a professional discipline such as medicine is able to conduct clinical studies using devices that have been consistently demonstrated to be inaccurate. One may argue that the methodology used to evaluate these systems (mean percentage error, concordance) is not appropriate and presents intrinsic limitations. However, would any other industry dealing with life and death situations accept such a shortcoming? Would an altimeter be used on a commercial passenger plane despite the fact that it has been demonstrated to be inaccurate according to the most commonly accepted standards from the Federal Aviation Administration? Why would we, as physicians, accept what other industries would clearly consider unacceptable?

The reason for this shortcoming is probably related to the fact that human physiology and physiopathology is an incredibly complex model. This explains why it is so difficult to reliably measure physiological variables, and it also explains why it is so difficult to make good clinical decisions. As a matter of fact, when dealing with complex situations, medical decision-making can be completely different from one physician to the next [26]. This lack of standardization in patient management is probably one of the major factors influencing patient outcome and, coincidentally, one of the only factors that we can influence for the improvement of patient care. This has been beautifully demonstrated during the past 10 years by studies in the critical care setting focusing on protocol implementation and quality improvement processes aiming at standardizing patient care. Goal-directed therapy protocols or checklist implementations exemplify this type of approach [105-107]. Studies such as those conducted by Rivers and colleagues in septic patients showing the impact of standardizing hemodynamic management on survival have opened the field to such approaches [9]. Most recently, studies have demonstrated that applying a simple checklist in the ICU and in the operating room can significantly impact outcome $[108,109]$. These studies are repeatedly concluding that decreasing the variability of care can save lives.

Concerning hemodynamic monitoring systems, the same approach could be applied. Clearly, despite the lack of precision of most $\mathrm{CO}$ monitoring systems available, some positive outcome studies have been published, especially in the perioperative setting with patients undergoing high-risk surgery. These studies have shown that the optimization of fluid administration based on $\mathrm{CO}$ monitoring can decrease postoperative morbidity and decrease the length of stay in the hospital and in the ICUs (Figure 1) [37,104]. Since fluid and hemodynamic 


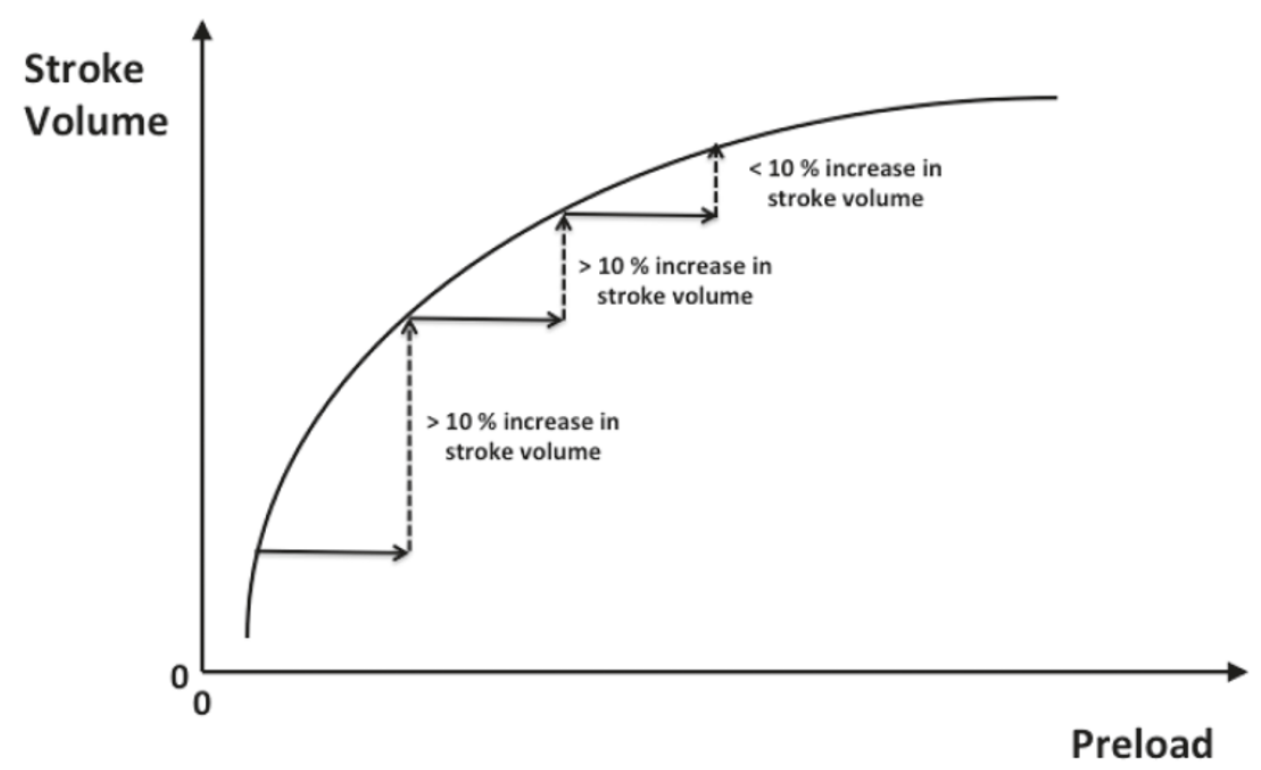

Figure 1. Fluid optimization concept based on stroke volume monitoring. The concept of cardiac output maximization based on fluid administration and stroke volume monitoring. Small boluses of fluid are administered intravenously (200 to $250 \mathrm{ml}$ at a time) until the stroke volume increases by $<10 \%$.

management have been shown to impact postoperative outcome and because these two major focuses of our field have been shown to be widely nonstandardized [110,111], it would then be reasonable to assume that using a $\mathrm{CO}$ monitoring system (even if not a perfect one) to guide fluid administration in a standardized way in the perioperative period has the potential to improve postoperative outcome. This approach consists of titrating fluid, based on $\mathrm{CO}$, until it reaches the plateau of the Frank-Starling relationship (Figure 1), which has been shown in several small clinical studies to improve patient outcome.

The evidence has been considered strong enough by the National Health Service in the UK to universally endorse this practice in the high-risk surgery setting $[42,43]$, even though it is has created some heated discussion [112,113]. Widespread acceptance of this concept in other countries will probably take longer due to the relative infrequency of large clinical studies. Such evaluations are strongly needed in the perioperative period $[11,114]$. This is exemplified by Devereaux and colleagues in an editorial recently published in Anesthesiology [114]: 'Unlike cardiology, large clinical studies remain uncommon in perioperative medicine $[115,116]$. Further, there has been a tendency to believe the results of small perioperative clinical studies, especially when they demonstrate statistically significant results. This position is supported by the fact that perioperative guideline committees recommended $\beta$-blockers to patients undergoing noncardiac surgery for a decade based upon the results of small trials demonstrating implausibly large treatment effects'. One should also mention that large qualityimprovement programs and comparative effectiveness research studies could also be utilized as an alternative to this approach [40,117].

In addition, while functional hemodynamic parameters can be used as diagnostic tools to answer whether a patient needs fluid or not, another approach consists of using these parameters to guide fluid optimization during high-risk surgery [10]. As a matter of fact, the concept of CO maximization during surgery could be achieved by applying the concept of respiratory variations in arterial pressure or in the plethysmographic waveform minimization (Figure 2) [10]. Conducting CO maximization using $\mathrm{CO}$ monitors that have $>40 \%$ mean percentage error [103] could theoretically be easily achieved by conducting PPV minimization. This would be a cheap and free-of-right way to optimize hemodynamics in the perioperative period. PPV minimization has been suggested and recently described [10,118], and the method could be of major importance in countries or institutions where the use of $\mathrm{CO}$ monitoring systems cannot be reasonably expected for all patients undergoing high-risk surgery but where fluid optimization still has the potential to dramatically influence patient outcome [119]. Of course, it may be difficult to determine the clinical effect of minimizing PPV without $\mathrm{CO}$ trending ability. However, recent studies strongly suggest that changes in PPV induced by volume expansion reflect changes in $\mathrm{CO}$ with excellent sensitivity, specificity, and a very narrow gray zone [120]. 


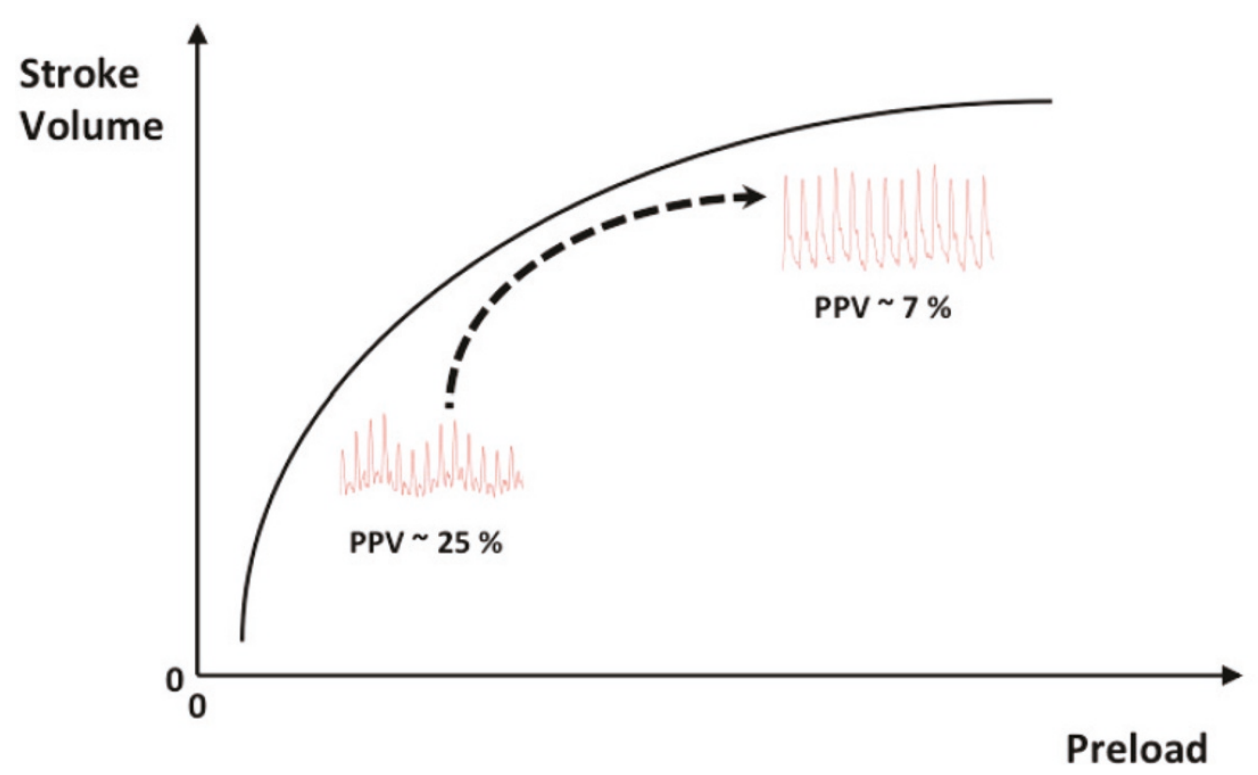

Figure 2. Fluid optimization concept based on minimization of dynamic parameters of fluid responsiveness. The concept of cardiac output maximization based on the minimization of dynamic parameters of fluid responsiveness. This minimization can be achieved by monitoring pulse pressure variation (PPV), stroke volume variation or respiratory variations in the plethysmographic waveform.

\section{Which hemodynamic monitoring system? For which patient? When? How?}

Several parameters must be considered before deciding which hemodynamic monitoring system should be used because, yes, it does eventually matter. Ideally, this decision should be made at the institutional level. Most departments throughout the world cannot afford to buy all of the market-available systems. At the same time, no system available today can effectively be used in all the different sectors of a hospital. Depending on the patient's specific history and course through the hospital, one hemodynamic monitoring system may be more appropriate than the other. Defining a set of systems available that will be adaptable to the various patient populations and clinical pathways will then be essential. This approach has been recently proposed by Alhashemi and colleagues (Figure 3) and has been described as an integrative perspective for the use of $\mathrm{CO}$ monitoring systems [3]. The defining approach takes into account the setting (ward, emergency department, operating room, and ICU) as well as the integration of $\mathrm{CO}$ monitoring with or without other hemodynamic variables.

\section{The decision should be an institutional decision and should integrate all clinical pathways existing within the institution}

Institutions containing emergency departments, operating rooms, and ICUs should have non-invasive, miniinvasive and invasive hemodynamic monitoring systems available to the clinicians and his or her patients. Likewise, when the institution performs cardiac surgery, it is still highly recommended to have PACs available. This system is well fitted for patients with low ejection fraction $(<30$ to $35 \%$ ), moderate to severe pulmonary hypertension, sepsis (endocarditis), and for cardiac transplantation. If the patient spends more than 72 hours in the ICU after surgery, it is recommended to switch from the PAC to a transpulmonary thermodilution system. Of course, transesophageal echocardiography should be available in all institutions performing cardiac surgery. However, this system is not a monitoring system per se and does not substitute for a continuous hemodynamic monitoring system.

An important consideration is that patient management is a continuum of care. Consequently, it is essential to maintain compatibility among hemodynamic monitoring technologies between different departments within the institution and to favour systems able to adapt to various clinical pathways. For example, some patients will enter the hospital through the emergency department, will then go to the operating room, and then to the ICU. Ideally, the evolution in hemodynamic monitoring should be made available on an identical platform that will adapt to the changes in hemodynamic status of the patient as well as to the clinical scenario in these different departments. Today, technological platforms allowing for a continuum of care from a totally non-invasive hemodynamic monitoring system to a mini-invasive one and then to an invasive one (or vice versa) are just emerging. For an institution to work within a given 


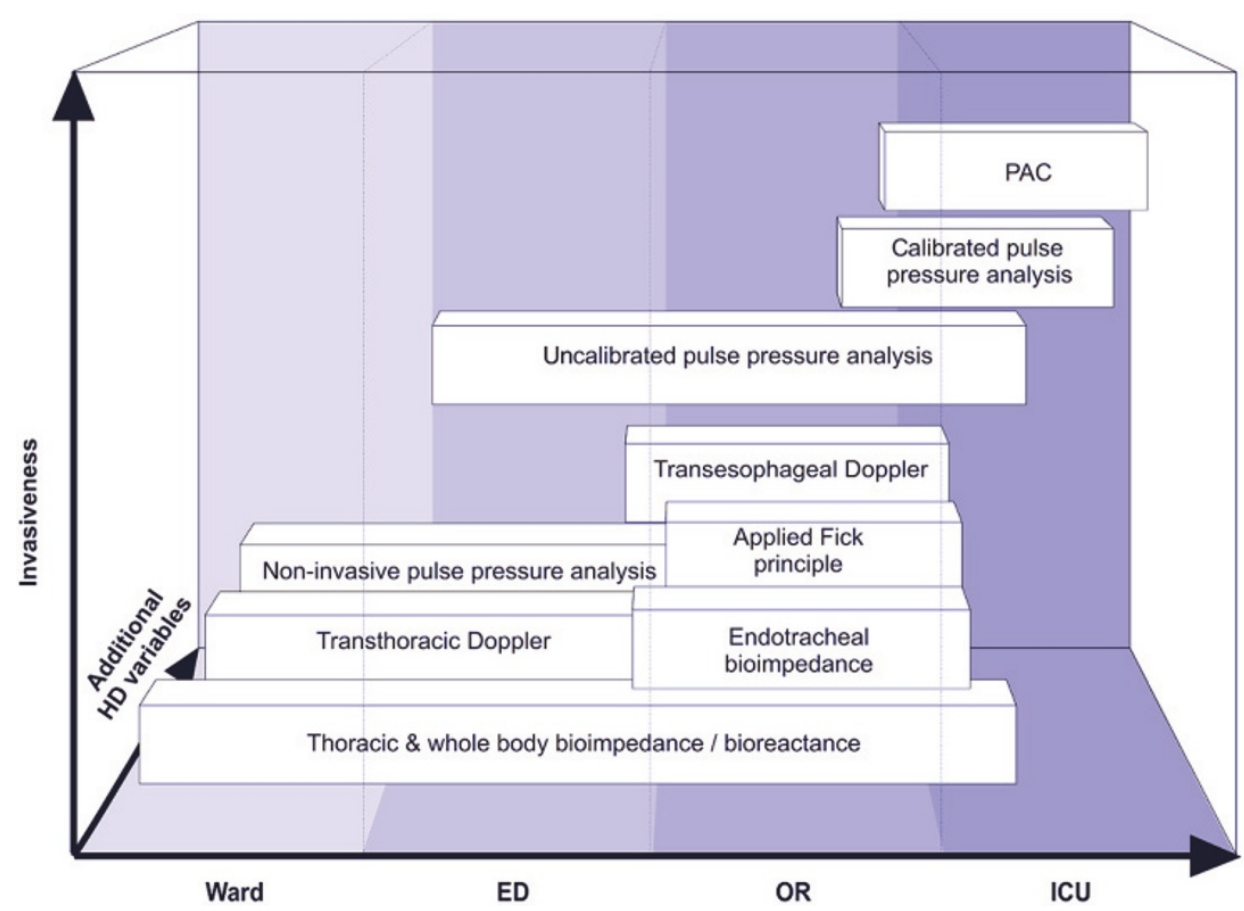

Figure 3. Integrative hemodynamic monitoring approach. ED, emergency department; HD, hemodynamic; OR, operating room; PAC, pulmonary artery catheter. Reproduced with permission from Alhashemi and colleagues [3].

system that would be flexible and allow any kind of patient throughout the hospital to be effectively monitored would make perfect sense. Once again, this kind of platform is just starting to emerge and most institutions still have to purchase different systems, from different companies, in order to monitor different patients.

The systems should be paired with clearly defined protocols As mentioned earlier, the only way to impact patient outcome is to pair the monitoring system with a therapeutic protocol. This approach has been shown to improve perioperative outcome in several small clinical studies and in some quality improvement processes employing the esophageal Doppler [40]. Such standardization of patient care is the only way to change current practice and to pragmatically and positively impact clinical decision-making. Standardization guidelines should also include the indications for hemodynamic monitoring and which hemodynamic monitoring system should be used for what patients (based on the integrative approach described above; Figure 3). Once again, the National Health Service in the UK has exemplified this through its release of National Institute for Health and Clinical Excellence guidance regarding hemodynamic monitoring and optimization during high-risk surgery $[42,43]$. These guidelines are clear and easy to apply and can easily be applied in any institution.

\section{The system should be adapted to the patient}

Of course, the final choice of a hemodynamic monitoring system is patient and pathology dependent. Additionally, whenever possible, a non-invasive system should be used. However, at this stage, non-invasive systems may not be as reliable as invasive ones. There is no doubt that noninvasive systems will eventually take the lead in the future [121], but we are still contemplating the effective length of a development phase [122]. For example, non-invasive systems based on pulse oximeter waveform analysis have been shown to be able to provide useful information regarding fluid responsiveness in healthy patients under general anesthesia [85]. However, these systems may not be reliable in the ICU in septic shock patients [123]. That being said: who would consider managing the hemodynamic status of a septic shock patient based solely on the plethysmographic waveform alone? On one hand, the risk of using a non-invasive technique in a challenging setting is that it will lead to inappropriate clinical decisions. On the other hand, it is unacceptable to expand the indications for invasive monitoring when their risks outweigh their benefits. We should always keep this in mind when choosing the most appropriate hemodynamic monitor for our patients.

\section{Conclusion}

Hemodynamic monitoring and management has greatly improved during the past decade. Technologies have 
evolved from very invasive to non-invasive, and the philosophy has shifted from a static approach to a functional approach. However, the critical care community still has potential to improve its ability to adopt the most modern standards of research methodology in order to more effectively evaluate new monitoring systems and their impact on patient outcome. Today, despite the huge enthusiasm raised by new hemodynamic monitoring systems, there is still a big gap between clinical research studies evaluating these monitors and clinical practice. A few studies, especially in the perioperative period, have shown that hemodynamic monitoring systems coupled with treatment protocols can improve patient outcome. Unfortunately these trials are small and, overall, the corpus of science related to this topic does not yet fit the standard of clinical research methodology encountered in other specialties such as cardiology and oncology. Larger randomized trials, quality improvement processes, and comparative effectiveness research studies are probably needed. However, some innovative professional societies have considered that this evidence was strong enough to release recommendations regarding hemodynamic monitoring and management during high-risk surgery. For this purpose, strictly speaking, the esophageal Doppler is the device that currently presents with the most positive evidence.

Finally, the choice of the hemodynamic monitoring systems available should be a widespread institutional process and all departments involved should be consulted (emergency department, ward, ICU, and operating room). At the end of the day, the choice depends on the available expertise, on the patient population, and on the clinical pathways. For institutions who cannot afford a proprietary hemodynamic monitoring system for their patients, fluid optimization can be achieved effectively by monitoring respiratory variations in the arterial pressure or in the plethysmographic waveform depending on the clinical context.

This is part of a series on Perioperative monitoring, edited by Dr Andrew Rhodes

\section{Abbreviations}

$\mathrm{CO}$, cardiac output; PAC, pulmonary artery catheter; PPV, pulse pressure variation.

\section{Competing interests}

DR is a consultant and speaker for Edwards Lifesciences. MC is a consultant for Masimo Corp., Edwards Lifesciences, Covidien, Draeger, Philips Medical Systems, Fresenius Kabi, and a speaker for ConMed. MC received research grants from Edwards Lifesciences and Masimo Corp. MC is co-inventor and co-owner on US and International patent applications related to closedloop fluid administration and hold an equity positions in Sironis, a company developing closed-loop medical devices. BA declares that he has no competing interests.

Published: 5 March 2013
References

1. Pinsky MR, Payen D: Functional hemodynamic monitoring. Crit Care 2005, 9:566-572.

2. Alhashemi JA, Cecconi M, della Rocca G, Cannesson M, Hofer CK: Minimally invasive monitoring of cardiac output in the cardiac surgery intensive care unit. Curr Heart Fail Rep 2010, 7:116-124.

3. Alhashemi JA, Cecconi M, Hofer CK: Cardiac output monitoring: an integrative perspective. Crit Care 2011, 15:214.

4. Marik PE: Noninvasive cardiac output monitors: a state-of the-art review. J Cardiothorac Vasc Anesth 2012. [Epub ahead of print]

5. Hadian M, Pinsky MR: Functional hemodynamic monitoring. Curr Opin Crit Care 2007, 13:318-323.

6. Vincent JL, Pinsky MR, Sprung CL, Levy M, Marini JJ, Payen D, Rhodes A, Takala J: The pulmonary artery catheter: in medio virtus. Crit Care Med 2008, 36:3093-3096.

7. Pinsky MR, Vincent JL: Let us use the pulmonary artery catheter correctly and only when we need it. Crit Care Med 2005, 33:1119-1122.

8. Vincent JL, Rhodes A, Perel A, Martin GS, Della Rocca G, Vallet B, Pinsky MR, Hofer CK, Teboul JL, de Boode WP, Scolletta S, Vieillard-Baron A, De Backer D, Walley KR, Maggiorini M, Singer M: Clinical review: Update on hemodynamic monitoring - a consensus of 16. Crit Care 2011, 15:229.

9. Rivers E, Nguyen B, Havstad S, Ressler J, Muzzin A, Knoblich B, Peterson E, Tomlanovich M: Early goal-directed therapy in the treatment of severe sepsis and septic shock. N Engl J Med 2001, 345:1368-1377.

10. Cannesson M: Arterial pressure variation and goal-directed fluid therapy. J Cardiothorac Vasc Anesth 2010, 24:487-497.

11. Macdonald N, Pearse RM: Peri-operative hemodynamic therapy: only large clinical trials can resolve our uncertainty. Crit Care 2011, 15:122.

12. Moller JT, Johannessen NW, Espersen $K$, Ravlo $O$, Pedersen $B D$, Jensen PF Rasmussen NH, Rasmussen LS, Pedersen T, Cooper JB, Gravenstein JS, Chraemmer-Jørgensen B, Djernes M, Wiberg-Jørgensen F, Heslet L, Johansen SH: Randomized evaluation of pulse oximetry in 20,802 patients: II. Perioperative events and postoperative complications. Anesthesiology 1993, 78:445-453.

13. Moller JT, Pedersen T, Rasmussen LS, Jensen PF, Pedersen BD, Ravlo O, Rasmussen NH, Espersen K, Johannessen NW, Cooper JB, Gravenstein JS, Chraemmer-Jorgensen B, Wiberg-Jorgensen F, Djernes M, Heslet L, Johansen SH: Randomized evaluation of pulse oximetry in 20,802 patients: I. Design, demography, pulse oximetry failure rate, and overall complication rate. Anesthesiology 1993, 78:436-444.

14. Shanewise JS, Cheung AT, Aronson S, Stewart WJ, Weiss RL, Mark JB, Savage RM, Sears-Rogan P, Mathew JP, Quinones MA, Cahalan MK, Savino JS: ASE/ SCA guidelines for performing a comprehensive intraoperative multiplane transesophageal echocardiography examination: recommendations of the American Society of Echocardiography Council for Intraoperative Echocardiography and the Society of Cardiovascular Anesthesiologists Task Force for Certification in Perioperative Transesophageal Echocardiography. Anesth Analg 1999, 89:870-884.

15. Hofer CK, Cecconi M, Marx G, della Rocca G: Minimally invasive haemodynamic monitoring. Eur J Anaesthesiol 2009, 26:996-1002.

16. Ganz W, Donoso R, Marcus HS, Forrester JS, Swan HJ: A new technique for measurement of cardiac output by thermodilution in man. Am J Cardiol 1971, 27:392-396.

17. Ganz W, Swan HJ: Measurement of blood flow by thermodilution. Am J Cardio/ 1972, 29:241-246.

18. Swan HJ, Ganz W, Forrester J, Marcus H, Diamond G, Chonette D: Catheterization of the heart in man with use of a flow-directed balloontipped catheter. N Engl J Med 1970, 283:447-451.

19. Shoemaker WC, Appel PL, Kram HB, Waxman K, Lee TS: Prospective trial of supranormal values of survivors as therapeutic goals in high-risk surgical patients. Chest 1988, 94:1176-1186.

20. Wiener RS, Welch HG: Trends in the use of the pulmonary artery catheter in the United States, 1993-2004. JAMA 2007, 298:423-429.

21. Rubenfeld GD, McNamara-Aslin E, Rubinson L: The pulmonary artery catheter, 1967-2007: rest in peace? JAMA 2007, 298:458-461.

22. Wheeler AP, Bernard GR, Thompson BT, Schoenfeld D, Wiedemann HP, deBoisblanc B, Connors AF Jr, Hite RD, Harabin AL: Pulmonary-artery versus central venous catheter to guide treatment of acute lung injury. N Engl J Med 2006, 354:2213-2224

23. Connors AF Jr, Speroff T, Dawson NV, Thomas C, Harrell FE Jr, Wagner D, Desbiens N, Goldman L, Wu AW, Califf RM, Fulkerson WJ Jr, Vidaillet H, Broste 
S, Bellamy P, Lynn J, Knaus WA: The effectiveness of right heart catheterization in the initial care of critically ill patients. SUPPORT Investigators. JAMA 1996, 276:889-897.

24. Shah MR, Hasselblad V, Stevenson LW, Binanay C, O'Connor CM, Sopko G, Califf RM: Impact of the pulmonary artery catheter in critically ill patients: meta-analysis of randomized clinical trials. JAMA 2005, 294:1664-1670.

25. Sandham JD, Hull RD, Brant RF, Knox L, Pineo GF, Doig CJ, Laporta DP, Viner S, Passerini L, Devitt H, Kirby A, Jacka M: A randomized, controlled trial of the use of pulmonary-artery catheters in high-risk surgical patients. N Engl J Med 2003, 348:5-14.

26. Squara $P$, Bennett $D$, Perret $C:$ Pulmonary artery catheter: does the problem lie in the users? Chest 2002, 121:2009-2015.

27. Shepherd SJ, Pearse RM: Role of central and mixed venous oxygen saturation measurement in perioperative care. Anesthesiology 2009, 111:649-656.

28. Gan TJ, Arrowsmith JE: The oesophageal Doppler monitor. BMJ 1997 315:893-894.

29. Tomlin PJ, Duck FA: Proceedings: aortic velography in man. Br J Anaesth 1975, 47:908

30. Duck FA, Hodson CJ, Tomlin PJ: An esophageal Doppler probe for aortic flow velocity monitoring. Ultrasound Med Biol 1974, 1:233-241.

31. Sinclair S, James S, Singer M: Intraoperative intravascular volume optimisation and length of hospital stay after repair of proximal femoral fracture: randomised controlled trial. BMJ 1997, 315:909-912

32. Gan TJ, Soppitt A, Maroof M, el-Moalem H, Robertson KM, Moretti E, Dwane P, Glass PS: Goal-directed intraoperative fluid administration reduces length of hospital stay after major surgery. Anesthesiology 2002, 97:820-826.

33. Venn R, Steele A, Richardson P, Poloniecki J, Grounds M, Newman P: Randomized controlled trial to investigate influence of the fluid challenge on duration of hospital stay and perioperative morbidity in patients with hip fractures. Br J Anaesth 2002, 88:65-71.

34. Wakeling HG, MCFall MR, Jenkins CS, Woods WG, Miles WF, Barclay GR, Fleming SC: Intraoperative oesophageal Doppler guided fluid management shortens postoperative hospital stay after major bowe surgery. Br J Anaesth 2005, 95:634-642.

35. Lefrant JY, Bruelle P, Aya AG, Saissi G, Dauzat M, de La Coussaye JE, Eledjam JJ: Training is required to improve the reliability of esophageal Doppler to measure cardiac output in critically ill patients. Intensive Care Med 1998, 24:347-352

36. Cannesson M, Pestel G, Ricks C, Hoeft A, Perel A: Hemodynamic monitoring and management in patients undergoing high risk surgery: a survey among North American and European anesthesiologists. Crit Care 2011 15:R197.

37. Hamilton MA, Cecconi M, Rhodes A: A systematic review and meta-analysis on the use of preemptive hemodynamic intervention to improve postoperative outcomes in moderate and high-risk surgical patients. Anesth Analg 2011, 112:1392-1402.

38. Conway DH, Mayall R, Abdul-Latif MS, Gilligan S, Tackaberry C: Randomised controlled trial investigating the influence of intravenous fluid titration using oesophageal Doppler monitoring during bowel surgery. Anaesthesia 2002, 57:845-849.

39. Roche AM, Miller TE, Gan TJ: Goal-directed fluid management with transoesophageal Doppler. Best Pract Res Clin Anaesthesio/ 2009, 23:327-334.

40. Kuper M, Gold SJ, Callow C, Quraishi T, King S, Mulreany A, Bianchi M, Conway DH: Intraoperative fluid management guided by oesophageal Doppler monitoring. BMJ 2011, 342:d3016

41. Noblett SE, Snowden CP, Shenton BK, Horgan AF: Randomized clinical trial assessing the effect of Doppler-optimized fluid management on outcome after elective colorectal resection. Br J Surg 2006, 93:1069-1076

42. Medical Technologies Guidance MTG3: CardioQ-ODM Oesophageal Doppler Monitor [http://www.nice.org.uk/MTG3]

43. NICE Draft Guidance on Cardiac Output Monitoring Device Published for Consultation [http://www.nice.org.uk/newsroom/pressreleases/ DraftGuidanceOnCardiacOutputMonitoringDevice.jsp]

44. Goedje O, Hoeke K, Lichtwarck-Aschoff M, Faltchauser A, Lamm P, Reichart B: Continuous cardiac output by femoral arterial thermodilution calibrated pulse contour analysis: comparison with pulmonary arterial thermodilution. Crit Care Med 1999, 27:2407-2412.

45. Bendjelid K, Giraud R, Siegenthaler N, Michard F: Validation of a new transpulmonary thermodilution system to assess global end-diastolic volume and extravascular lung water. Crit Care 2010, 14:R209.
46. Kiefer N, Hofer CK, Marx G, Geisen M, Giraud R, Siegenthaler N, Hoeft A, Bendjelid K, Rex S: Clinical validation of a new thermodilution system for the assessment of cardiac output and volumetric parameters. Crit Care 2012, 16:R98.

47. Della Rocca G, Costa MG, Pompei L, Coccia C, Pietropaoli P: Continuous and intermittent cardiac output measurement: pulmonary artery catheter versus aortic transpulmonary technique. Br J Anaesth 2002, 88:350-356

48. Della Rocca G, Costa MG, Coccia C, Pompei L, Di Marco P, Vilardi V, Pietropaol $P$ : Cardiac output monitoring: aortic transpulmonary thermodilution and pulse contour analysis agree with standard thermodilution methods in patients undergoing lung transplantation. Can J Anaesth 2003, 50:707-711.

49. Cottis R, Magee N, Higgins DJ: Haemodynamic monitoring with pulseinduced contour cardiac output (PiCCO) in critical care. Intensive Crit Care Nurs 2003, 19:301-307.

50. Cecconi M, Dawson D, Grounds RM, Rhodes A: Lithium dilution cardiac output measurement in the critically ill patient: determination of precision of the technique. Intensive Care Med 2009, 35:498-504.

51. Belda FJ, Aguilar G, Teboul JL, Pestana D, Redondo FJ, Malbrain M, Luis JC, Ramasco F, Umgelter A, Wendon J, Kirov M, Fernandez-Mondejar E: Complications related to less-invasive haemodynamic monitoring. $\mathrm{Br} J$ Anaesth 2011, 106:482-486.

52. Bendjelid $\mathrm{K}$ : When to recalibrate the PiCCO? From a physiological point of view, the answer is simple. Acta Anaesthesiol Scand 2009, 53:689-690.

53. Hamzaoui O, Monnet X, Richard C, Osman D, Chemla D, Teboul JL: Effects of changes in vascular tone on the agreement between pulse contour and transpulmonary thermodilution cardiac output measurements within an up to 6-hour calibration-free period. Crit Care Med 2008, 36:434-440.

54. Monnet X, Anguel N, Naudin B, Jabot J, Richard C, Teboul JL: Arterial pressure-based cardiac output in septic patients: different accuracy of pulse contour and uncalibrated pressure waveform devices. Crit Care 2010 14:R109.

55. Monnet X, Letierce A, Hamzaoui O, Chemla D, Anguel N, Osman D, Richard C, Teboul JL: Arterial pressure allows monitoring the changes in cardiac output induced by volume expansion but not by norepinephrine. Crit Care Med 2011, 39:1394-1399.

56. Goepfert MS, Reuter DA, Akyol D, Lamm P, Kilger E, Goetz AE: Goal-directed fluid management reduces vasopressor and catecholamine use in cardiac surgery patients. Intensive Care Med 2007, 33:96-103.

57. Funk DJ, Moretti EW, Gan TJ: Minimally invasive cardiac output monitoring in the perioperative setting. Anesth Analg 2009, 108:887-897.

58. Pratt B, Roteliuk L, Hatib F, Frazier J, Wallen RD: Calculating arterial pressurebased cardiac output using a novel measurement and analysis method. Biomed Instrum Technol 2007, 41:403-411.

59. Meng L, Tran NP, Alexander BS, Laning K, Chen G, Kain ZN, Cannesson M: The impact of phenylephrine, ephedrine, and increased preload on thirdgeneration Vigileo-FloTrac and esophageal Doppler cardiac output measurements. Anesth Analg 2011, 113:751-757.

60. Monnet X, Anguel N, Jozwiak M, Richard C, Teboul JL: Third-generation FloTrac/Vigileo does not reliably track changes in cardiac output induced by norepinephrine in critically ill patients. Br J Anaesth 2012, 108:615-622.

61. Cecconi M, Fasano N, Langiano N, Divella M, Costa MG, Rhodes A, Della Rocca G: Goal directed haemodynamic therapy during elective total hip arthroplasty under regional anaesthesia. Crit Care 2011, 15:R132

62. Mayer J, Boldt J, Mengistu AM, Rohm KD, Suttner S: Goal-directed intraoperative therapy based on autocalibrated arterial pressure waveform analysis reduces hospital stay in high-risk surgical patients: a randomized, controlled trial. Crit Care 2010, 14:R18.

63. Marque S, Cariou A, Chiche JD, Squara P: Comparison between FlotracVigileo and Bioreactance, a totally noninvasive method for cardiac output monitoring. Crit Care 2009, 13:R73.

64. Squara P, Rotcajg D, Denjean D, Estagnasie P, Brusset A: Comparison of monitoring performance of Bioreactance vs. pulse contour during lung recruitment maneuvers. Crit Care 2009, 13:R125.

65. Kossari N, Hufnagel G, Squara P: Bioreactance: a new tool for cardiac output and thoracic fluid content monitoring during hemodialysis. Hemodial Int 2009, 13:512-517.

66. Benomar B, Ouattara A, Estagnasie P, Brusset A, Squara P: Fluid responsiveness predicted by noninvasive bioreactance-based passive leg raise test. Intensive Care Med 2010, 36:1875-1881.

67. Squara P, Denjean D, Estagnasie P, Brusset A, Dib JC, Dubois C: Noninvasive cardiac output monitoring (NICOM): a clinical validation. Intensive Care Med 
2007, 33:1191-1194.

68. Raval NY, Squara P, Cleman M, Yalamanchili K, Winklmaier M, Burkhoff D: Multicenter evaluation of noninvasive cardiac output measurement by bioreactance technique. J Clin Monit Comput 2008, 22:113-119.

69. Chen G, Meng L, Alexander B, Tran NP, Kain ZN, Cannesson M: Comparison of noninvasive cardiac output measurements using the Nexfin monitoring device and the esophageal Doppler. J Clin Anesth 2012, 24:275-283.

70. Broch O, Renner J, Gruenewald M, Meybohm P, Schottler J, Caliebe A, Steinfath M, Malbrain M, Bein B: A comparison of the Nexfin and transcardiopulmonary thermodilution to estimate cardiac output during coronary artery surgery. Anaesthesia 2012, 67:377-383.

71. Michard $\mathrm{F}$ : Changes in arterial pressure during mechanical ventilation. Anesthesiology 2005, 103:419-428.

72. Perel A, Pizov R, Cotev S: Systolic blood pressure variation is a sensitive indicator of hypovolemia in ventilated dogs subjected to graded hemorrhage. Anesthesiology 1987, 67:498-502.

73. Coriat P, Vrillon M, Perel A, Baron JF, Le Bret F, Saada M, Viars P: A comparison of systolic blood pressure variations and echocardiographic estimates of end-diastolic left ventricular size in patients after aortic surgery. Anesth Analg 1994, 78:46-53.

74. Tavernier B, Makhotine O, Lebuffe G, Dupont J, Scherpereel P: Systolic pressure variation as a guide to fluid therapy in patients with sepsisinduced hypotension. Anesthesiology 1998, 89:1313-1321.

75. Marik PE, Cavallazzi R, Vasu T, Hirani A: Dynamic changes in arterial waveform derived variables and fluid responsiveness in mechanically ventilated patients: a systematic review of the literature. Crit Care Med 2009, 37:2642-2647.

76. Feissel M, Michard F, Faller JP, Teboul JL: The respiratory variation in inferior vena cava diameter as a guide to fluid therapy. Intensive Care Med 2004, 30:1834-1837.

77. Barbier C, Loubieres Y, Schmit C, Hayon J, Ricome JL, Jardin F, Vieillard-Baron A: Respiratory changes in inferior vena cava diameter are helpful in predicting fluid responsiveness in ventilated septic patients. Intensive Care Med 2004, 30:1740-1746

78. Vieillard-Baron A, Chergui K, Rabiller A, Peyrouset O, Page B, Beauchet A, Jardin F: Superior vena caval collapsibility as a gauge of volume status in ventilated septic patients. Intensive Care Med 2004, 30:1734-1739.

79. De Backer D, Pinsky MR: Can one predict fluid responsiveness in spontaneously breathing patients? Intensive Care Med 2007, 33:1111-1113.

80. Cannesson M, Tran NP, Cho M, Hatib F, Michard F: Predicting fluid responsiveness with stroke volume variation despite multiple extrasystoles. Crit Care Med 2012, 40:193-198.

81. De Backer D, Heenen S, Piagnerelli M, Koch M, Vincent JL: Pulse pressure variations to predict fluid responsiveness: influence of tidal volume. Intensive Care Med 2005, 31:517-523.

82. Reuter DA, Goepfert MS, Goresch T, Schmoeckel M, Kilger E, Goetz AE: Assessing fluid responsiveness during open chest conditions. Br J Anaesth 2005, 94:318-323.

83. Monnet X, Rienzo M, Osman D, Anguel N, Richard C, Pinsky MR, Teboul JL: Passive leg raising predicts fluid responsiveness in the critically ill. Crit Care Med 2006, 34:1402-1407.

84. Monnet X, Osman D, Ridel C, Lamia B, Richard C, Teboul JL: Predicting volume responsiveness by using the end-expiratory occlusion in mechanically ventilated intensive care unit patients. Crit Care Med 2009, 37:951-956.

85. Cannesson M, Attof Y, Rosamel P, Desebbe O, Joseph P, Metton O, Bastien O, Lehot JJ: Respiratory variations in pulse oximetry plethysmographic waveform amplitude to predict fluid responsiveness in the operating room. Anesthesiology 2007, 106:1105-1111.

86. Marik PE, Baram M, Vahid B: Does central venous pressure predict fluid responsiveness?: a systematic review of the literature and the tale of seven mares. Chest 2008, 134:172-178.

87. Desebbe O, Cannesson M: Using ventilation induced plethysmographic variations to optimize patient fluid status. Curr Opin Anaesthesio/ 2008 , 21:772-778

88. Forget $\mathrm{P}$, Lois F, de Kock M: Goal-directed fluid management based on the pulse oximeter-derived pleth variability index reduces lactate levels and improves fluid management. Anesth Analg 2010, 111:910-914.

89. Cecconi M, Rhodes A: Validation of continuous cardiac output technologies: consensus still awaited. Crit Care 2009, 13:159.

90. Cecconi M, Dawson D, Casaretti R, Grounds RM, Rhodes A: A prospective study of the accuracy and precision of continuous cardiac output monitoring devices as compared to intermittent thermodilution. Minerva Anestesiol 2010, 76:1010-1017

91. Cecconi M, Grounds M, Rhodes A: Methodologies for assessing agreement between two methods of clinical measurement: are we as good as we think we are? Curr Opin Crit Care 2007, 13:294-296.

92. Cecconi M, Hofer C, Della Rocca G, Grounds RM, Rhodes A: Assessing agreement in cardiac output monitoring validation studies. J Cardiothorac Vasc Anesth 2010, 24:741; author reply 741-742.

93. Bland JM, Altman DG: Statistical methods for assessing agreement between two methods of clinical measurement. Lancet 1986, 1:307-310.

94. Bland JM, Altman DG: Agreement between methods of measurement with multiple observations per individual. J Biopharm Stat 2007, 17:571-582.

95. Critchley LA, Critchley JA: A meta-analysis of studies using bias and precision statistics to compare cardiac output measurements techniques. J Clin Monit Comput 1999, 15:85-91.

96. Cecconi M, Rhodes A, Poloniecki J, Della Rocca G, Grounds RM: Bench-tobedside review: the importance of the precision of the reference technique in method comparison studies - with specific reference to the measurement of cardiac output. Crit Care 2009, 13:201.

97. Critchley LA, Lee A, Ho AM: Review article: A critical review of the ability of continuous cardiac output monitors to measure trends in cardiac output. Anesth Analg 2010, 111:1180-1192.

98. Squara P, Cecconi M, Rhodes A, Singer M, Chiche JD: Tracking changes in cardiac output: methodological considerations for the validation of monitoring devices. Intensive Care Med 2009, 35:1801-1808.

99. Feldman JM: Is it a bird? Is it a plane? The role of patients monitors in medical decision making. Anesth Analg 2009, 108:707-710.

100. Michard F, Boussat S, Chemla D, Anguel N, Mercat A, Lecarpentier Y, Richard $C$, Pinsky MR, Teboul JL: Relation between respiratory changes in arterial pulse pressure and fluid responsiveness in septic patients with acute circulatory failure. Am J Respir Crit Care Med 2000, 162:134-138.

101. Ray P, Le Manach Y, Riou B, Houle TT: Statistical evaluation of a biomarker. Anesthesiology 2010, 112:1023-1040.

102. Feinstein AR: The inadequacy of binary models for the clinical reality of three-zone diagnostic decisions. J Clin Epidemio/ 1990, 43:109-113.

103. Peyton PJ, Chong SW: Minimally invasive measurement of cardiac output during surgery and critical care: a meta-analysis of accuracy and precision. Anesthesiology 2010, 113:1220-1235

104. Rhodes A, Cecconi M, Hamilton M, Poloniecki J, Woods J, Boyd O, Bennett D, Grounds RM: Goal-directed therapy in high-risk surgical patients: a 15-year follow-up study. Intensive Care Med 2010, 36:1327-1332.

105. Haynes AB, Weiser TG, Berry WR, Lipsitz SR, Breizat AH, Dellinger EP, Dziekan G, Herbosa T, Kibatala PL, Lapitan MC, Merry AF, Reznick RK, Taylor B, Vats A, Gawande AA: Changes in safety attitude and relationship to decreased postoperative morbidity and mortality following implementation of a checklist-based surgical safety intervention. Qual Saf Health Care 2011 20:102-107.

106. Semel ME, Resch S, Haynes AB, Funk LM, Bader A, Berry WR, Weiser TG, Gawande AA: Adopting a surgical safety checklist could save money and improve the quality of care in U.S. hospitals. Health Aff (Millwood) 2010 , 29:1593-1599.

107. Weiser TG, Haynes AB, Dziekan G, Berry WR, Lipsitz SR, Gawande AA: Effect of a 19-item surgical safety checklist during urgent operations in a global patient population. Ann Surg 2010, 251:976-980.

108. Haynes AB, Weiser TG, Berry WR, Lipsitz SR, Breizat AH, Dellinger EP, Herbosa T, Joseph S, Kibatala PL, Lapitan MC, Merry AF, Moorthy K, Reznick RK, Taylor B, Gawande AA: A surgical safety checklist to reduce morbidity and mortality in a global population. N Engl J Med 2009, 360:491-499.

109. Pronovost P, Needham D, Berenholtz S, Sinopoli D, Chu H, Cosgrove S, Sexton B, Hyzy R, Welsh R, Roth G, Bander J, Kepros J, Goeschel C: An intervention to decrease catheter-related bloodstream infections in the ICU. N Engl J Med 2006, 355:2725-2732.

110. Pearse RM, Holt PJ, Grocott MP: Managing perioperative risk in patients undergoing elective non-cardiac surgery. BMJ 2011, 343:d5759.

111. Pearse RM, Ackland GL: Perioperative fluid therapy. BMJ 2012, 344:e2865.

112. Singer M: Oesophageal Doppler monitoring: a not-so-NICE editorial. Anaesthesia 2012, 67:428-430; author reply 431-432.

113. Singer M: Management of fluid balance: a European perspective. Curr Opin Anaesthesio/ 2012, 25:96-101.

114. Devereaux PJ, Chan MT, Eisenach J, Schricker T, Sessler DI: The need for large 
clinical studies in perioperative medicine. Anesthesiology 2012, 116:1169-1175.

115. Kelly MJ, Wadsworth J: What price inconclusive clinical trials? Ann R Coll Surg Engl 1993, 75:145-146.

116. Pua HL, Lerman J, Crawford MW, Wright JG: An evaluation of the quality of clinical trials in anesthesia. Anesthesiology 2001, 95:1068-1073.

117. Michard F, Cannesson M, Vallet B: Perioperative hemodynamic therapy: quality improvement programs should help to resolve our uncertainty. Crit Care 2011, 15:445.

118. Benes J, Chytra I, Altmann P, Hluchy M, Kasal E, Svitak R, Pradl R, Stepan M: Intraoperative fluid optimization using stroke volume variation in high risk surgical patients: results of prospective randomized study. Crit Care 2010, 14:R118.

119. Maitland K, Kiguli S, Opoka RO, Engoru C, Olupot-Olupot P, Akech SO, Nyeko R, Mtove G, Reyburn H, Lang T, Brent B, Evans JA, Tibenderana JK, Crawley J, Russell EC, Levin M, Babiker AG, Gibb DM: Mortality after fluid bolus in African children with severe infection. N Engl J Med 2011, 364:2483-2495.

120. Le Manach Y, Hofer CK, Lehot JJ, Vallet B, Goarin JP, Tavernier B, Cannesson M: Can changes in arterial pressure be used to detect changes in cardiac output during volume expansion in the perioperative period? Anesthesiology 2012. [Epub ahead of print]

121. Cannesson M, Rinehart J: Innovative technologies applied to anesthesia: how will they impact the way we practice? J Cardiothorac Vasc Anesth 2012 26:711-720.

122. Cannesson M, Desebbe O, Lehot JJ: Fluid responsiveness assessment using the pulse oxymeter waveform: not yet ready for prime time. Anesth Analg 2007, 104:1598-1599; author reply 1599-1600.

123. Landsverk SA, Hoiseth LO, Kvandal P, Hisdal J, Skare O, Kirkeboen KA: Poor agreement between respiratory variations in pulse oximetry photoplethysmographic waveform amplitude and pulse pressure in intensive care unit patients. Anesthesiology 2008, 109:849-855.

doi:10.1186/cc11814

Cite this article as: Ramsingh D, et al.: Clinical review: Does it matter which hemodynamic monitoring system is used? Critical Care 2013, 17:208. 